\title{
The Use of Saxagliptin in People with Type 2 Diabetes in France: The Diapazon Epidemiological Study
}

Beverley Balkau (D) B Bernard Charbonnel - Alfred Penfornis ·

Nora Chraibi · Amir Lahouegue $\cdot$ Céline Faure $\cdot$ Florence Thomas-Delecourt •

Bruno Detournay

Received: July 3, 2017 / Published online: September 25, 2017

(C) The Author(s) 2017. This article is an open access publication

\section{ABSTRACT}

Introduction: Saxagliptin is a potent, reversible inhibitor of dipeptidyl peptidase- 4 that is indicated for the treatment of type 2 diabetes. The DIAPAZON study was a multicenter observational study intended to document the effectiveness, safety and patterns of saxagliptin use in France, including the saxagliptin retention rate, over 2 years of follow-up.

Methods: A geographically representative sample of 304 French physicians (general practitioners and specialist endocrinologists or

Enhanced content To view enhanced content for this article go to http://www.medengine.com/Redeem/ 2E1CF0601E532F1E.

B. Balkau · A. Penfornis

CESP, Faculty of Medicine, University Paris-South,

Orsay, France

B. Balkau

Faculty of Medicine, University Versailles-St

Quentin, Versailles, France

B. Balkau $(\square)$

INSERM U1018, University Paris-Saclay, Villejuif, France

e-mail: beverley.balkau@inserm.fr

B. Charbonnel

Service endocrinologie-maladies métaboliques et nutrition, CHU Nantes, Nantes, France diabetologists) recruited 1131 adults with type 2 diabetes into an ambispective cohort; 1033 fulfilled the inclusion criteria. All had started saxagliptin during the previous 6 months or at study inclusion, and follow-up was for $24 \pm 3$ months after starting saxagliptin.

Results: The mean age of the study population when starting saxagliptin was 61 years, and the mean $\mathrm{HbA1c}$ level was 8.0\%; 79\% had an HbA1c level $\geq 7 \%$. Prior to starting saxagliptin treatment, most participants (91\%) were receiving treatment with oral glucose-lowering drugs alone. The most commonly prescribed regimen at starting saxagliptin (53\% of participants) was a combination of saxagliptin and metformin. The overall saxagliptin retention rate at 2 years was $79 \%$, as estimated by the Kaplan-Meier

\section{A. Penfornis}

Service de diabétologie-endocrinologie, CHSF, Corbeil Essonnes, Université Paris-Sud, Orsay, France

N. Chraibi · A. Lahouegue · F. Thomas-Delecourt AstraZeneca, Courbevoie, France

C. Faure

Mapi, Lyon, France

B. Detournay

Cemka-Eval, Bourg-La-Reine, France 
method. The most common reasons for discontinuation were inadequate glycemic control $(52 \%)$ and intolerance (22\%). During the course of the study, the mean HbA1c level decreased to $7.0 \%$, and the percentage of people with HbA1c $<7 \%$ increased from $21 \%$ to $49 \%$. The mean change in body weight was $-1.8 \mathrm{~kg}$. A total of 294 hypoglycemic episodes were reported in 70 participants $(6.8 \%)$ during the follow-up period. Of these, 143 episodes in 41 participants (4.0\%) occurred when saxagliptin was used in combination with agents associated with hypoglycemia, such as insulin, sulfonylureas or glinides.

Conclusion: Saxagliptin is efficacious and well tolerated in a real-world practice setting, with almost $80 \%$ of participants remaining on treatment after 2 years.

Funding: AstraZeneca, France.

Keywords: Diabetes mellitus; Hypoglycemic agents; Observational study; Saxagliptin; Type 2 diabetes

\section{INTRODUCTION}

Diabetes is a significant and growing global health problem. Recent data from the International Diabetes Federation indicate that worldwide about 415 million people $(8.8 \%$ of adults aged 20-79 years) have diabetes, and it is anticipated that this figure will increase to 642 million (10.4\% of the adult population) by 2040 [1]. In France, approximately 3.3 million people (5.0\% of the population) have diabetes [2], and the prevalence has increased by $2.3 \%$ per annum between 2009 and 2013 [3]. In developed countries, $95 \%$ of adults with diabetes have type 2 diabetes, reflecting increasingly sedentary lifestyles, adiposity and adverse dietary factors [1].

Treatment options for type 2 diabetes have expanded in recent years, with the introduction of a number of new classes of medication, including glucagon-like peptide-1 (GLP-1) agonists, and more recently dipeptidyl peptidase- 4 (DPP-4) inhibitors [4]. The latter act by inhibiting the breakdown of GLP-1, thereby increasing circulating concentrations of this peptide.
GLP-1 is responsible for $50-70 \%$ of glucose-dependent insulin secretion, [5] and hence inhibition of GLP-1 breakdown resulting in increased peripheral glucose utilization, decreased hepatic glucose production, and improvements in both postprandial glycemia and fasting plasma glucose $[6,7]$ of $4.7 \mathrm{~g} \mathrm{~min} / \mathrm{dl}$ and $13 \mathrm{mg} / \mathrm{dl}$, respectively, in comparison to controls [7]. In addition, DPP-4 inhibitors do not adversely affect body weight and have been shown to improve $\beta$-cell function [7]. Clinical trials in diverse patient populations with type 2 diabetes have shown that DPP-4 inhibitors are effective in improving glycemic control and have a low risk of hypoglycemia (although this may increase when used in combination with agents associated with hypoglycemia, such as insulin or sulfonylureas) $[8,9]$.

Currently available DPP-4 inhibitors differ markedly in their pharmacologic characteristics, and this may have implications for their clinical efficacy and safety profiles [10, 11]. Saxagliptin is a potent, reversible, competitive DPP-4 inhibitor with high selectivity for human DPP-4 and a potency approximately tenfold greater than that of vildagliptin or sitagliptin $[9,12]$. Administration of saxagliptin after a meal or after an oral glucose dose results in a two- to three-fold increase in circulating GLP-1 concentrations, decreases in circulating glucagon concentrations, and hence a reduction in post-prandial glucose levels, with an improvement in $\beta$-cell responsiveness to glucose [9]. The efficacy and safety of saxagliptin in people with type 2 diabetes have been extensively investigated in both monotherapy $[13,14]$ and combination therapy [15-21] settings. Saxagliptin has been available in France as monotherapy $\left(\right.$ Onglyza $\left.^{\circledR}\right)$ since September 2010 and in a fixed-dose combination with metformin (Komboglyze $^{\circledR}$ ) since November 2012. As a condition of marketing, the Transparency Committee of the French Haute Autorité de Santé (HAS) requested a long-term cohort study to document the efficacy and safety of saxagliptin in patients with type 2 diabetes under real-world conditions. The results of this study, the Description of Drug Utilization and Assessment of Impact of Saxagliptin on Health Status of Patients with 
Type 2 Diabetes in France (DIAPAZON) study, are presented here.

\section{METHODS}

The DIAPAZON study was a multicenter observational study of people in France with type 2 diabetes starting treatment with saxagliptin, who were recruited by a representative sample of French general practitioners (GPs) and specialists (endocrinologists and diabetologists). The primary objectives of the study were to describe the demographic and clinical characteristics of the population starting saxagliptin and patterns of saxagliptin use and to evaluate the saxagliptin retention rate, changes in glycated hemoglobin $(\mathrm{HbA} 1 \mathrm{c})$ and body weight, and the incidence of hypoglycemia during saxagliptin treatment over 2 years.

All procedures followed were in accordance with the ethical standards of the responsible committees on human experimentation (institutional and national) at each participating institution and with the Helsinki Declaration of 1964. Informed oral consent was obtained from all participants included in the study. In accordance with European regulations, ethical approval was not necessary for this observational study, because no additional therapy or monitoring was required. All data processing was carried out in compliance with French Information Technology and Privacy laws.

\section{Physician Recruitment}

Participating physicians were identified from the TVF database (Cegedim, Boulogne-Billancourt, France). Initially, invitation letters were sent between May and September 2012 to 16,000 randomly selected GPs, stratified by French administrative region. This sample size was based on the assumption that positive responses would be obtained from $10 \%$ to $20 \%$ of invited physicians. However, it was necessary to invite a further sample of approximately 16,000 newly selected GPs at the end of 2012 to achieve the required number of participating GPs (see below). All endocrinologists or diabetologists included in the TVF database
( $n=1013)$ were invited to take part in the study.

\section{Study Population}

This study involved an ambispective cohort of adults (aged $\geq 18$ years) with type 2 diabetes who consulted a participating physician for any reason during a 2-month inclusion period (subsequently increased to 9 months because of low inclusion rates) and who had started saxagliptin treatment during the 6 months prior to inclusion or at study inclusion. The only exclusion criterion was participation in a clinical trial.

\section{Follow-up}

Participants were followed for $24 \pm 3$ months after starting saxagliptin, and all data obtained during this time were included in the analysis. Participants who discontinued saxagliptin treatment during this period were retained in the study and followed until the end of the follow-up period. The primary endpoints, which were based on physicians' reports, included socio-demographics; clinical characteristics and comorbidities; saxagliptin use (dosage and concomitant medications); compliance with the therapeutic indications for saxagliptin $[22,23]$ and clinical guidance in force at the time of the study [24]; compliance with the reimbursed therapeutic indications, as defined by the French state health insurance fund for salaried workers [Caisse Nationale de l'Assurance Maladie des Travailleurs Salariés, (CNAMTS)] [25]; saxagliptin discontinuation rates and reasons for discontinuation (saxagliptin was considered to have been permanently discontinued when a prescription that did not include saxagliptin was issued at least 30 days after the last prescription of saxagliptin); changes in HbA1c and body weight during saxagliptin treatment; mean number of severe hypoglycemic episodes and adverse events. Severe hypoglycemic events were defined as symptomatic hypoglycemic episodes requiring outside assistance or 
hospitalization due to severe alterations of consciousness or behavior.

\section{Statistical Methods}

\section{Sample Size Calculation}

The sample size calculated was designed to ensure that the study provided meaningful information on the use and impact of saxagliptin by focusing on two variables: the saxagliptin retention rate at 2 years and the percentage of participants with an HbA1c level $<7 \%$ during the study. It was estimated that a sample size of 1000 participants would allow the saxagliptin retention rate at 2 years to be estimated with an acceptable precision of $\pm 2.5 \%$. Similarly, assuming that HbA1c data would be available for $90 \%$ of participants at the end of the study, it was estimated that a sample size of 900 participants would allow the percentage with $\mathrm{HbA} 1 \mathrm{c}<7 \%$ to be described with a precision of $\pm 3.3 \%$.

It was considered reasonable to ask each participating physician to enroll two people into the ambispective cohort, and hence it would be necessary to recruit 500 physicians to achieve a sample size of 1000 patients. Assuming that approximately $80 \%$ of people with type 2 diabetes are managed by GPs, it was therefore necessary to recruit approximately 400 GPs and 100 specialists.

\section{Statistical Analyses}

Comparisons between participating physicians and a geographically representative sample of French physicians drawn from the 2012 Research, Studies, Evaluation and Statistics Division [Direction de la recherche, des études, de l'évaluation et des statistiques, (DREES)] database [26], and comparisons between people included and not included in the ambispective cohort, were made using Student's $t$ tests for continuous variables and $\chi^{2}$ or Fisher's exact tests for categorical variables.

Analyses of baseline data were purely descriptive; to minimize potential bias arising from the sampling method, weights related to frequency of consultation and physician sampling frame were applied for each patient included in the ambispective cohort for descriptive analyses only, except for analyses of safety data during follow-up (adverse events, hypoglycemia and comorbidities). Separate analyses were also performed according to the investigator's specialty (GP or endocrino logy/diabetology).

Saxagliptin retention rates at 6, 12, 18 and 24 months were calculated by the Kaplan-Meier method. A conservative methodology was used, whereby all premature withdrawals from the study were considered to be discontinuations of saxagliptin therapy.

HbA1c values over time and changes in body weight from baseline to the end of follow-up were estimated by mixed models for repeated measures. Models included site and participant as random effects and time from diagnosis to saxagliptin initiation, age at saxagliptin initiation, physician specialty and body weight at baseline (only in the model to analyze change in weight) as fixed effects. Furthermore, additional factors were individually tested in the models at the $P<0.2$ level. Final models were determined by backward selection of factors at a significance level of $P<0.05$. The additional factors were gender, baseline body mass index (BMI), tobacco use, physical exercise and compliance with therapeutic indications [22, 23] and glucose-lowering treatment prescribed at initiation.

This study was registered on ClinicalTrials.gov: NCT01552005. All analyses were performed using $\mathrm{SAS}^{\circledR}$ version 9.2 (SAS Institute, Cary, NC, USA) and $\operatorname{AdClin}^{\circledR}$ version 3.3.1 (AdClin, Paris, France) software, and $P$ values below 0.05 were considered significant.

\section{RESULTS}

\section{Physician Recruitment}

A total of 33,010 physicians were contacted, of whom 1032 agreed to participate in the study. Of these, 814 (78.9\%) responded before the quota of participating physicians had been reached; of these, 667 (81.9\%) completed the administrative procedure and participated in the study and $304(45.6 \%)$ recruited at least one 
Table 1 Demographic characteristics of physicians enrolling patients (participating physicians) compared with a geographically representative sample of French physicians derived from the Direction de la recherche, des études, de l'évaluation et des statistiques (DREES) database [26]

\begin{tabular}{lll}
\hline & General practitioners & \\
\cline { 2 - 3 } & Participating physicians $(\boldsymbol{n}=\mathbf{2 4 5})$ & DREES database $(\boldsymbol{n}=\mathbf{1 0 1} \mathbf{8 0 3})$ \\
\hline Age (mean, years) & 53.4 & 51.4 \\
Male & $85.4 \%$ & $58.4 \%$ \\
Type of practice & & \\
Private & $93.8 \%$ & $62.5 \%$ \\
Public & $2.2 \%$ & $17.0 \%$ \\
Mixed & $4.0 \%$ & $5.5 \%$ \\
Other & 0 & $15.0 \%$ \\
\hline & Endocrinologists/diabetologists & \\
\cline { 2 - 3 } & Participating physicians $(\boldsymbol{n}=\mathbf{5 9})$ & $\mathbf{D R E E S ~ d a t a b a s e ~}(\boldsymbol{n}=\mathbf{1 7 3 7})$ \\
\hline Age (mean, years) & 48.9 & 47.9 \\
Male & $37.3 \%$ & $26.8 \%$ \\
Type of practice & & \\
Private & $33.9 \%$ & $32.8 \%$ \\
Public & $41.1 \%$ & $48.3 \%$ \\
Mixed & $25.0 \%$ & $14.9 \%$ \\
Other & 0 & $4.0 \%$ \\
\hline
\end{tabular}

patient into the ambispective cohort. Of the 304 "active" physicians, $80.6 \%$ were GPs, and $19.4 \%$ were specialists (Table 1 ). Their mean $( \pm \mathrm{SD})$ age was $52 \pm 8$ years, and $76 \%$ were male. A majority of participating general practitioners were in private practice $(93.8 \%)$; in contrast, $33.9 \%$ of endocrinologists/diabetologists were in private practice, $41.1 \%$ practiced in the public sector, and $25.0 \%$ had a mixed practice. Almost all of the participating physicians (93.5\%) had at least one patient who was receiving saxagliptin prior to their participation in the study. Compared with the participating physicians, non-participating physicians (those who refused to participate or did not return financial agreements before inclusion) were more likely to be female (23\% versus $43 \%$, respectively), work in the public sector $(7.5 \%$ versus $18.4 \%$ ) and have no patients receiving saxagliptin (6.5\% versus $40.9 \%)$.

The demographic characteristics of the 304 active physicians are summarized in Table 1 and compared with those of a geographically representative sample of French physicians drawn from the DREES database [26]. The two populations were generally comparable, except for a higher percentage of males and a much higher percentage of general practitioners in private practice among the participating physicians.

Data collection for the ambispective cohort took place from 22 June 2012, and the mean duration of follow-up was 20.9 months [95\% confidence interval (CI) 20.4-21.4]; $73.6 \%$ of participants were followed for 24 months. A total of 24 physicians discontinued their participation during the study, resulting in 56 
people with type 2 diabetes being lost to follow-up.

\section{Study Population}

A total of 1131 participants were enrolled into the ambispective cohort, of whom 98 (8.7\%) were subsequently excluded; the most common reason for exclusion $(n=81,82.7 \%)$ was no treatment with saxagliptin started at enrollment or in the 6 months prior to enrollment. Thus, the analysis of the ambispective cohort included 1033 participants, of whom 97.5\% were treated with saxagliptin and the remainder with a saxagliptin/metformin fixed-dose combination. Overall, 777 participants $(75.2 \%)$ were enrolled by GPs; the mean number of patients enrolled by each active physician was 3.6 (range $1-8)$.

\section{Clinical Characteristics}

The clinical characteristics of participants in the ambispective cohort at the time of starting saxagliptin are summarized in Table 2 . The mean age of the patients at the time of diagnosis of type 2 diabetes was 54.3 years (95\% CI 53.6-55.1), and the mean age at starting saxagliptin was 61.2 years (95\% CI 60.4-61.9). The mean BMI at baseline was $29.8 \mathrm{~kg} / \mathrm{m}^{2}(95 \%$ CI $29.5-30.2$ ), and $83.9 \%$ of patients were overweight (BMI $\left.\geq 25 \mathrm{~kg} / \mathrm{m}^{2}\right)$. The mean HbA1c level at baseline was $8.0 \%$ (95\% CI 7.9-8.1\%), and $79 \%$ of patients had an HbA1c level $\geq 7 \%$.

Overall, $26.9 \%$ of the participants had at least one microvascular diabetic complication, and these were more likely to be enrolled by specialists than by GPs. For macrovascular complications, $4.2 \%$ had angina pectoris, $5.1 \%$ a history of myocardial infarction, $2.5 \%$ a stroke and $1.6 \%$ heart failure. Treatment for dyslipidemia was prescribed for $62 \%$ of the population, and a similar percentage was prescribed antihypertensive therapy. Secondary cardiovascular prevention status was observed in 13\% of the patients, i.e., those patients presenting with angina, myocardial infarction, peripheral arterial disease or stroke when starting saxagliptin.
Patient selection biases were assessed by comparing data from included and non-included patients. Compared with non-included patients, included patients weighed slightly less $(P=0.041)$, had a lower BMI $(P=0.014)$, were younger at time of T2D diagnosis $(P=0.015)$, had been diagnosed with T2D for a longer period of time $(P<0.0001)$ and the last known HbA1c value before consultation was slightly lower $(P<0.0001)$.

\section{Glucose-Lowering Therapy}

Prior to starting saxagliptin, the majority of participants $(91.3 \%)$ were prescribed oral glucose-lowering drugs alone, with $6.0 \%$ prescribed either insulin or a GLP-1 analog alone or with oral drugs, and $2.8 \%$ were not receiving any glucose-lowering medication. Compared with GPs, specialists were slightly less likely to prescribe oral drugs alone and more likely to prescribe insulin. Among the participants receiving oral drugs alone, $66.4 \%$ were on monotherapy, $28.9 \%$ on dual therapy and $4.7 \%$ on combinations of three or more agents. Specialists were more likely than GPs to prescribe dual combination therapy: $35.1 \%$ of participants enrolled by specialists were receiving dual combination therapy compared with $27.0 \%$ of those enrolled by GPs. Metformin was the most commonly used oral glucose-lowering drug, accounting for $83.8 \%$ of people receiving monotherapy. The most widely used combination was metformin with a sulfonylurea, which was prescribed for $66.1 \%$ of people prescribed dual combination therapy. The mean doses of metformin in people on monotherapy and on dual combination therapy were $2032 \mathrm{mg} /$ day (95\% CI 1977-2087) and $2164 \mathrm{mg} /$ day (95\% CI 2087-2241 mg), respectively.

\section{Starting Saxagliptin Therapy}

For the majority of participants (97.4\%), saxagliptin was started by the participating physician, and for $61.2 \%$, saxagliptin was started at the time of enrollment into the study. The most commonly prescribed regimen $(52.9 \%)$ was a combination of saxagliptin and 
Table 2 Clinical characteristics of the 1033 participants at inclusion ${ }^{a}$

\begin{tabular}{|c|c|c|}
\hline & \multicolumn{2}{|c|}{ Physician specialty } \\
\hline & $\begin{array}{l}\text { General } \\
\text { practitioner } \\
N=777\end{array}$ & $\begin{array}{l}\text { Endocrinologist/diabetologist } \\
N=256\end{array}$ \\
\hline Age at starting saxagliptin (years) & $61.5 \pm 11.0$ & $59.9 \pm 13.8$ \\
\hline$<65$ years & $519(66.7 \%)$ & $173(67.6 \%)$ \\
\hline $65-75$ years & $156(20.0 \%)$ & $56(21.7 \%)$ \\
\hline $75-80$ years & $61(7.8 \%)$ & $14(5.6 \%)$ \\
\hline$>80$ years & $42(5.4 \%)$ & $13(5.2 \%)$ \\
\hline Time between diagnosis of diabetes and starting saxagliptin (years) & $6.7 \pm 6.2$ & $8.3 \pm 9.2$ \\
\hline \multicolumn{3}{|l|}{ Starting saxagliptin } \\
\hline At inclusion & $459(59.0 \%)$ & $174(68.0 \%)$ \\
\hline Before inclusion & $318(41.0 \%)$ & $82(32.0 \%)$ \\
\hline Weight $(\mathrm{kg})$ & $84.7 \pm 16.2$ & $85.7 \pm 19.7$ \\
\hline Body mass index $\left(\mathrm{kg} / \mathrm{m}^{2}\right)$ & $29.7 \pm 5.1$ & $30.3 \pm 5.8$ \\
\hline Last known $\mathrm{HbAlc}$ value (\%) & $8.0 \pm 1.3$ & $8.1 \pm 2.1$ \\
\hline $\begin{array}{l}\text { Time between last known HbAlc value and starting saxagliptin } \\
\text { (months) }\end{array}$ & $0.6 \pm 0.8$ & $0.5 \pm 0.9$ \\
\hline \multicolumn{3}{|l|}{ Macrovascular diabetic complications } \\
\hline Angina pectoris & $3.6 \%$ & $6.0 \%$ \\
\hline History of myocardial infarction & $3.9 \%$ & $8.5 \%$ \\
\hline Peripheral arterial occlusive disease of the lower limbs & $4.3 \%$ & $3.4 \%$ \\
\hline History of stroke & $2.6 \%$ & $2.1 \%$ \\
\hline Heart failure & $1.6 \%$ & $1.3 \%$ \\
\hline \multicolumn{3}{|l|}{ Microvascular diabetic complications } \\
\hline Any microvascular complication & $23.4 \%$ & $37.7 \%$ \\
\hline Retinopathy & $1.5 \%$ & $5.1 \%$ \\
\hline \multicolumn{3}{|l|}{ Renal impairment } \\
\hline Moderate $^{\mathrm{b}}$ & $11.2 \%$ & $12.2 \%$ \\
\hline Severe ${ }^{c}$ & 0 & $0.3 \%$ \\
\hline Microalbuminuria $^{\mathrm{d}}$ & $6.4 \%$ & $16.7 \%$ \\
\hline Proteinuria $^{\mathrm{e}}$ & $1.8 \%$ & $1.6 \%$ \\
\hline \multicolumn{3}{|l|}{ Cardiovascular risk factors } \\
\hline Current or recent ( $<3$ years) smoker & $21.0 \%$ & $10.9 \%$ \\
\hline No regular physical exercise & $66.6 \%$ & $54.8 \%$ \\
\hline
\end{tabular}


Table 2 continued

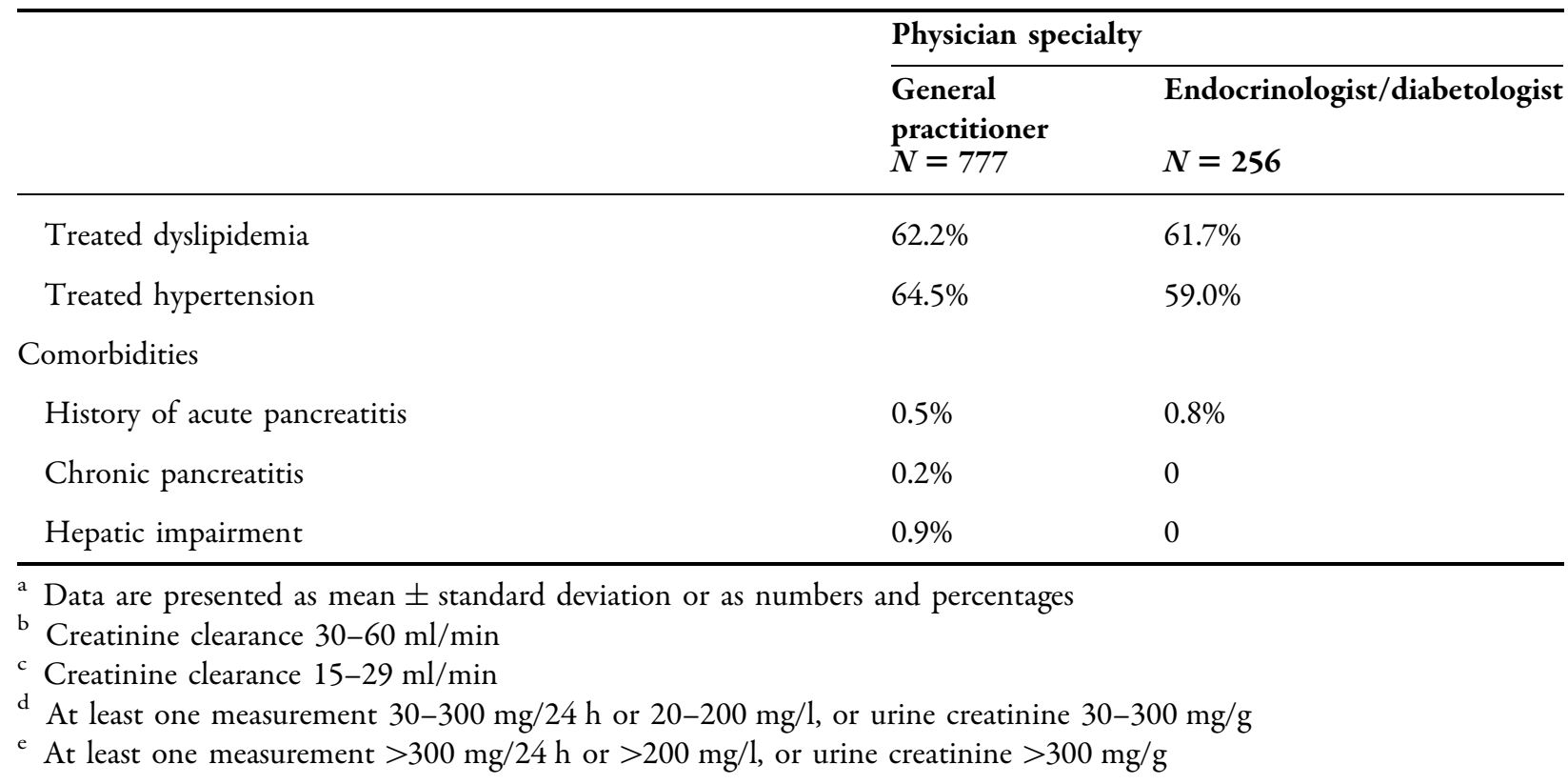

metformin; $15.1 \%$ were prescribed saxagliptin monotherapy, $15.6 \%$ a combination of saxagliptin, metformin and a sulfonylurea, and $6.1 \%$ a combination of saxagliptin with a sulfonylurea. Combination therapy with saxagliptin and metformin accounted for 55.3\% of prescriptions by GPs and $45.9 \%$ of prescriptions by specialists. The most common reason for starting saxagliptin was inadequate glycemic control, in $81 \%$ of the patient, followed by intolerance to the previous glucose-lowering therapy.

In total, 582 saxagliptin prescriptions (56.4\%) were in compliance with the therapeutic indications for saxagliptin and saxagliptin/metformin fixed-dose combination applicable at the time the data were analyzed $[22,23]$. The most common cause of non-compliance, accounting for $57.4 \%$ of non-compliant prescriptions, was the use of glucose-lowering medications prior to starting saxagliptin that were not specified in the therapeutic indications. Treatment with metformin alone should have been prescribed before starting saxagliptin; however, $6.3 \%$ of participants did not receive any treatment, $14.7 \%$ switched to saxagliptin from another DPP-4 inhibitor, and $36.4 \%$ received another treatment not specified in the therapeutic indications. In
$22.6 \%$ of participants, HbA1c values were outside the range specified in the French Guidance for Diabetic Treatment [24]; in $16.7 \%$, a saxagliptin-containing combination prescribed at starting saxagliptin was not indicated, and in $10.3 \%$ of cases, when saxagliptin was started in participants who had previously received metformin alone, it was not due to intolerance to metformin.

According to the definition used by the French authority CNAMTS [25], 92.7\% of saxagliptin prescriptions at baseline conformed to the therapeutic indications, and $76.7 \%$ met the conditions for reimbursement. Overall, 76.7\% were in compliance with both the therapeutic indications and the conditions for reimbursement.

\section{Retention of Saxagliptin Therapy}

The overall saxagliptin retention rate at 2 years, estimated by the Kaplan-Meier method, was 78.6\% (95\% CI 76.0-81.3). The retention rate was higher among participants enrolled by GPs than among those enrolled by specialists $(83.6 \%$ versus $58.3 \%$, respectively). Similar trends were seen at 6, 12 and 18 months (Fig. 1).

The most common reasons for discontinuation among the 112 patients who discontinued 
saxagliptin during the 2-year follow-up period were inadequate glycemic control (52.1\%) followed by intolerance $(21.8 \%)$, patient request $(14.2 \%)$ and poor adherence to therapy (7.8\%). Overall, the proportion of participants discontinuing treatment was three times higher among patients enrolled by specialists compared with those enrolled by GPs $(21.2 \%$ versus $7.4 \%$, respectively); participants enrolled by specialists were more likely to discontinue treatment because of poor tolerability $(25.8 \%$ versus $18.1 \%)$, but less likely to discontinue because of poor adherence $(4.2 \%$ versus $11.1 \%)$. The most common therapies prescribed following discontinuation of saxagliptin were metformin monotherapy (18.3\%), metformin plus a sulfonylurea (14.2\%), insulin (12.9\%) and insulin plus metformin (5.7\%).

\section{HbA1c and Weight Under Saxagliptin Therapy}

The mean $\mathrm{HbA} 1 \mathrm{c}$ at 2 years was $7.0 \%$, with $49 \%$ having an $\mathrm{HbA} 1 \mathrm{c}<7 \%$, increased from $21 \%$ prior to starting saxagliptin (Fig. 2). When tested individually, the factors retained to estimate the
HbA1c value over time were glucose-lowering treatment prescribed and regular physical exercise. These factors were subsequently confirmed in the final multivariable model with $P<0.0001$ and $P=0.0008$, respectively. Time from diagnosis to saxagliptin initiation, age at saxagliptin initiation, physician specialty and time were also found to significantly influence the HbA1c value over time $(P<0.0001$ for all effects). The mean HbA1c level estimated by the multivariable analyses decreased from $8.1 \%$ (95\% CI 7.9-8.2) at baseline to $7.1 \%(95 \%$ CI $7.0-7.3)$ at 2 years (Fig. 2). There was little difference between observed HbA1c levels over time and HbA1c values estimated by the multivariable analyses.

At 2 years, participants treated with saxagliptin showed a mean weight change of $-2.0 \mathrm{~kg}(95 \% \mathrm{CI}-2.4$ to -1.7$)$. No factors individually tested were statistically significant. Age at saxagliptin initiation $(P=0.0222)$, weight at baseline $(P<0.0001)$ and time from diagnosis to saxagliptin initiation $(P<0.0001)$ were found to significantly influence change in weight in the final model. Mean weight change at 2 years estimated by the multivariable analysis was $-1.8 \mathrm{~kg}(95 \% \mathrm{CI}-2.2$ to -1.5$)$.

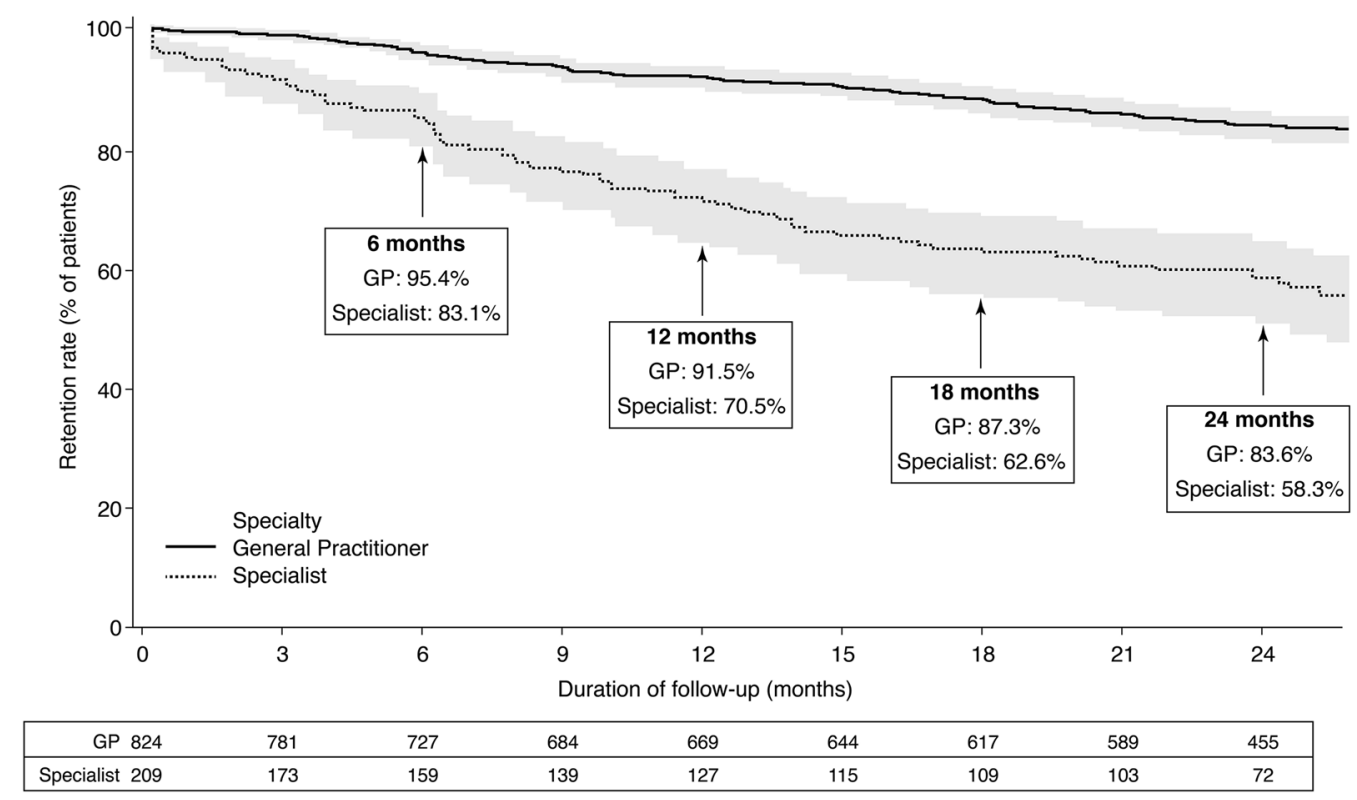

Fig. 1 Saxagliptin treatment retention rate (percentage of participants remaining on saxagliptin), estimated by the Kaplan-Meier method, over 2 years of follow- up, according to physician specialty. Shaded area indicates $95 \%$ confidence interval. Table below figure indicates number of patients still on treatment at each time point 


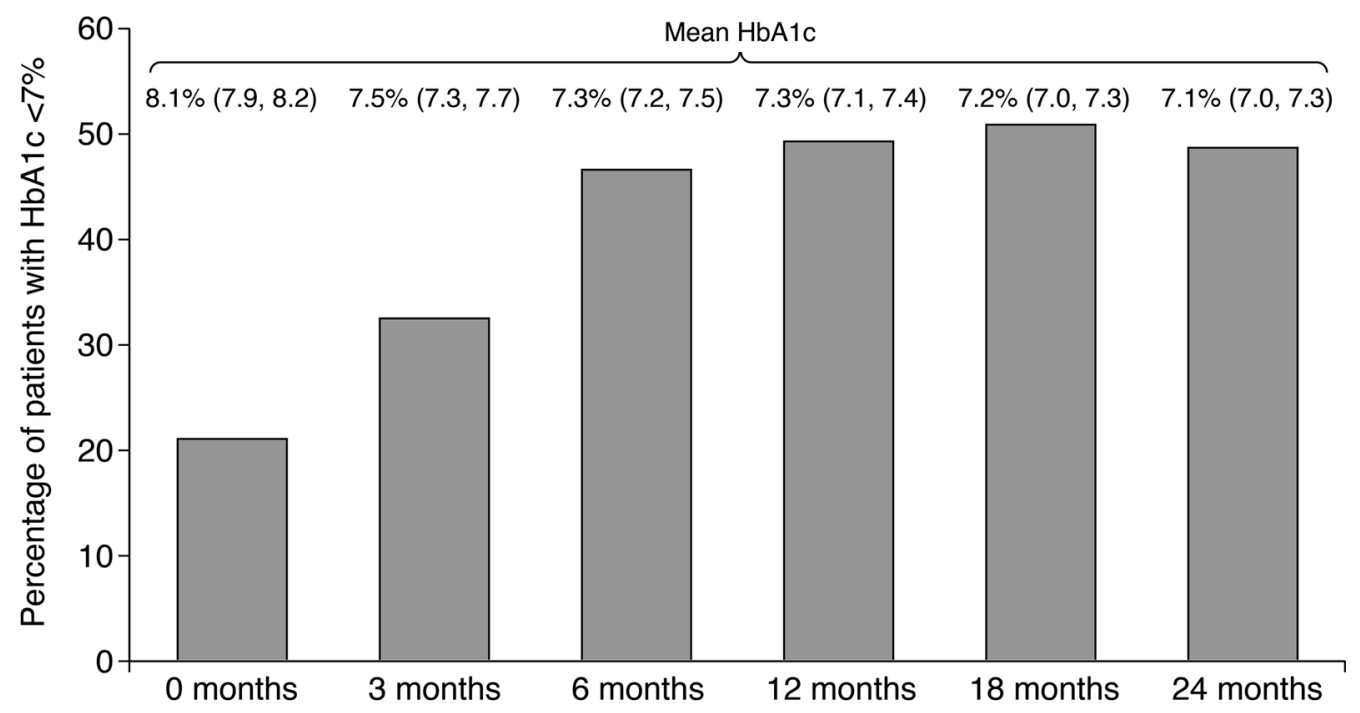

Fig. 2 Percentage of participants with HbAlc $<7 \%$ over the 2 years of follow-up, with weighting based on the frequency of consultation within the last 12 months or physicians' sample frame (specialty). The figures above each bar show the (unweighted) mean HbAlc level, with 95\% confidence interval (CI), at each time point, as

\section{Hypoglycemic Episodes, Adverse Events and Comorbidities Under Saxagliptin Therapy}

A total of 294 hypoglycemic episodes were reported in 70 participants $(6.8 \%)$ during the follow-up period. Of these, 143 episodes in 41 people $(4.0 \%)$ occurred while saxagliptin was prescribed in combination with agents associated with hypoglycemia, such as insulin, sulfonylureas or glinides. Seven severe hypoglycemic events occurred in six people $(0.6 \%)$, of whom one was prescribed saxagliptin with a sulfonylurea and one was prescribed saxagliptin plus insulin.

During the follow-up period, adverse events were reported in 228 participants $(22.1 \%)$, of whom $23(2.2 \%)$ experienced adverse events that were considered to be saxagliptin-related (Table 3). Serious adverse events occurred in 84 participants $(8.1 \%)$, of which 6 events in 2 participants were considered to be saxagliptin-related: one woman had increases in lipases and transaminases, and one man determined by a multivariable analysis adjusted for site and participants as random effects; time from diagnosis to saxagliptin initiation, age at saxagliptin initiation and physician specialty as fixed effects; and physical exercise and glucose-lowering treatment prescribed at initiation as covariates

reported loss of consciousness, speech disorder, hyperhidrosis and staring.

New comorbidities were reported in 102 participants $(11.7 \%)$; the majority $(n=80)$ developed renal disorders and 25 cardiovascular disease. Among the patients who developed renal disorders, $62(79.5 \%)$ had at least one episode of microalbuminuria, 6 (7.8\%) presented with renal impairment (creatinine clearance $<60 \mathrm{ml} / \mathrm{min}$ ), and 13 (19.4\%) presented with proteinuria. New cardiovascular diseases were not considered to be associated with saxagliptin treatment; seven people developed a stable angina pectoris, five a myocardial infarction, five a stroke, five peripheral arterial occlusive disease of the lower limbs and three heart failure.

\section{DISCUSSION}

DPP-4 inhibitors such as saxagliptin have an established place in the management of type 2 diabetes [9] and are recommended for use as monotherapy in people in whom metformin is 
Table 3 Incidence of adverse events considered to be saxagliptin-related

\begin{tabular}{|c|c|}
\hline & $\begin{array}{l}\text { Number of } \\
\text { patients (\%) }\end{array}$ \\
\hline Any saxagliptin-related adverse event & $23(100.0 \%)$ \\
\hline Eye disorders & $1(4.3 \%)$ \\
\hline Eye disorder & $1(4.3 \%)$ \\
\hline Eyelid edema & $1(4.3 \%)$ \\
\hline Gastrointestinal disorders & $12(52.2 \%)$ \\
\hline Diarrhea & $6(26.1 \%)$ \\
\hline Abdominal pain & $2(8.7 \%)$ \\
\hline Nausea & $2(8.7 \%)$ \\
\hline Upper abdominal pain & $1(4.3 \%)$ \\
\hline Stomatitis & $1(4.3 \%)$ \\
\hline Vomiting & $1(4.3 \%)$ \\
\hline $\begin{array}{l}\text { General disorders and administration } \\
\text { site conditions }\end{array}$ & $2(8.7 \%)$ \\
\hline Hyperhidrosis & $1(4.3 \%)$ \\
\hline Malaise & $1(4.3 \%)$ \\
\hline Hepatobiliary disorders & $1(4.3 \%)$ \\
\hline Cytolytic hepatitis & $1(4.3 \%)$ \\
\hline Investigations & $1(4.3 \%)$ \\
\hline Increased lipase & $1(4.3 \%)$ \\
\hline Increased transaminases & $1(4.3 \%)$ \\
\hline $\begin{array}{l}\text { Musculoskeletal and connective tissue } \\
\text { disorders }\end{array}$ & $1(4.3 \%)$ \\
\hline Arthralgia & $1(4.3 \%)$ \\
\hline Nervous system disorders & $4(17.4 \%)$ \\
\hline Dizziness & $1(4.3 \%)$ \\
\hline Headache & $1(4.3 \%)$ \\
\hline Loss of consciousness & $1(4.3 \%)$ \\
\hline Speech disorder & $1(4.3 \%)$ \\
\hline Vertigo & $1(4.3 \%)$ \\
\hline Psychiatric disorders & $1(4.3 \%)$ \\
\hline Staring & $1(4.3 \%)$ \\
\hline Renal and urinary disorders & $2(8.7 \%)$ \\
\hline
\end{tabular}

Table 3 continued

\begin{tabular}{cc}
\hline & $\begin{array}{l}\text { Number of } \\
\text { patients }(\%)\end{array}$ \\
\hline Microalbuminuria & $2(8.7 \%)$ \\
Skin and subcutaneous tissue disorders & $1(4.3 \%)$ \\
Urticaria & $1(4.3 \%)$ \\
\hline
\end{tabular}

contraindicated or poorly tolerated, as initial combination therapy with metformin in people with baseline HbA1c $\geq 7.5 \%$ [27] or $\geq 9.0 \%$ [28], or as add-on therapy with other oral glucose-lowering drugs if adequate glycemic control is not achieved with initial therapy $[28,29]$. The French recommendations for treatment with a DPP-4 are: in monotherapy (objective HbA1c $<6.5 \%$ ): DPP-4s are not reimbursed, even if it is recognized that they can be used when intolerance to other medications; in bitherapy (objective HbA1c <6.5\%): a DPP-4 with metformin or with a sulfonylurea; in tritherapy (objective HbA1c <7\%): a DPP-4 with metformin and sulfonylureas [30]. The efficacy and safety of saxagliptin in people with type 2 diabetes have been extensively documented in clinical trials $[9,29,31]$, while the long-term SAVOR-TIMI 53 study has shown that saxagliptin did not increase the composite risk for cardiovascular death, nonfatal myocardial infarction (MI) or nonfatal ischemic stroke when added to a patient's current standard of care (with or without other glucose-lowering therapies) as compared with placebo. However, there was an unexpected imbalance in the rate of hospitalizations for heart failure in the saxagliptin arm [32].

The results of the present study complement these findings by providing data on the use of saxagliptin in a large population followed under real-world conditions. Although such studies are at risk of selection bias due to the voluntary nature of physician involvement, and their interest in participating in a study if they prescribe saxagliptin, a comparison of the demographic data from participating and non-participating physicians showed few differences between the two groups. Furthermore, 
the characteristics of the participating physicians were comparable with those of a geographically representative sample of French physicians drawn from the 2012 DREES database, except for a higher percentage of males and a higher percentage of general practitioners in private practice among the participating physicians. The participating physicians can thus be considered representative of physicians practicing in France.

Participants enrolled in this study were broadly comparable with people with type 2 diabetes enrolled in the 2007-2010 French study ENTRED (échantillon national témoin représentatif des personnes diabétiques-National representative sample of people with diabetes) [33], which involved 4000 people with diabetes. Although there were statistically significant differences between the two populations in terms of age, time since diagnosis of diabetes and BMI, these were numerically small and of minimal clinical significance; these differences may be attributable to differences in patient enrollment methods between the two studies and to changes over time in the characteristics of people with type 2 diabetes in France as this study and the ENTRED study recruited over different time periods.

The frequencies of treatment for dyslipidemia and hypertension were similar to those seen in other French studies. In the 2012 ObEpi study [34], $60 \%$ of the people with type 2 diabetes were treated for lipids and 59\% for high blood pressure. These correspond well with the $62 \%$ and $63 \%$, respectively, observed in the present study. In the earlier 2007 ENTRED study $59 \%$ were treated for lipids, including $47 \%$ with statins [33].

The participants enrolled in the ambispective cohort were typical of people with type 2 diabetes encountered in routine clinical practice, in that a majority were receiving treatment for cardiovascular risk factors such as hypertension, dyslipidemia, or both, and about 5\% had a history of cardiovascular ischemic disease [angina pectoris. 4.2\%; MI, 5.1\%; stroke, (2.5\%); peripheral arterial disease, $4.0 \%)$ ]; in addition, about a quarter had microvascular disease (retinopathy and/or nephropathy). More than three quarters had inadequate glycemic control, indicated by an HbA1c level $\geq 7 \%$, before receiving saxagliptin. Prior to starting saxagliptin, the majority were receiving oral glucose-lowering medications alone, of whom about two-thirds were receiving monotherapy, primarily with metformin. Overall, approximately $56 \%$ of prescriptions conformed to the therapeutic indications for saxagliptin applicable at the time of the analysis. Prior to saxagliptin initiation, $3.2 \%$ were not receiving any glucose-lowering treatment, while $6.9 \%$ were receiving an alternative DPP-4 inhibitor that was replaced with saxagliptin. According to the definition used by the French authority CNAMTS, the percentage of people treated with saxagliptin who met both the therapeutic indications and the criteria for reimbursement was slightly higher than for DPP-4 inhibitors as a class (76.7\% versus $72.8 \%$ [25], respectively).

During the 2-year follow-up period, approximately $11 \%$ of participants discontinued saxagliptin treatment, and the 2-year retention rate was estimated to be $78.6 \%$. This is comparable with that reported in a French observational study with vildagliptin (VILDA) [35], as the retention rate in our study may have been underestimated because of premature withdrawals being reported as discontinuations without formal confirmation that patients were no longer receiving saxagliptin. This possibility is supported by the finding that 58 of 90 participants who were recorded as having discontinued treatment subsequently reported that they were still using saxagliptin.

The mean HbA1c level decreased from 8.0\% immediately before starting saxagliptin to $7.2 \%$ at 6 months and was subsequently maintained at this level throughout the follow-up period: at 2 years, $49 \%$ of participants had an HbA1c level $<7 \%$. These results are consistent with those of the VILDA study, in which the mean HbA1c had decreased by $0.8 \%$ at 2 years and $57.7 \%$ of participants achieved an HbA1c $<7 \%$ [35], and the Odyssée study [36], in which the mean HbA1c decreased by $0.6 \%$ in participants receiving a combination of sitagliptin with metformin.

Participants in this study showed a mean decrease in weight of approximately $2 \mathrm{~kg}$ over the 2 years after initiation of saxagliptin. This finding compares favorably with those of a 
recent meta-analysis of clinical trials with saxagliptin, in which saxagliptin had no clinically relevant effects on body weight, waist circumference or BMI, compared with controls [7]. DPP-4 inhibitors as a class have neutral effects on body weight [37], and this is an important advantage over certain other glucose-lowering therapies [7].

The overall incidence of adverse events in this study was $22.1 \%$, which compares favorably with the $72 \%$ reported in an analysis of pooled data from six phase III trials with saxagliptin [38]. The incidence of severe hypoglycemia $(0.6 \%)$ was similar to that reported in clinical trials [9]. Of the 294 hypoglycemic events reported during follow-up, approximately half occurred in people receiving saxagliptin concomitantly with insulin-secreting therapy (insulin, sulfonylurea or glinide). This is consistent with the experience reported in clinical trials $[9,29,31]$.

In our study, $2.4 \%$ of patients suffered a cardiovascular event but none was considered to be related with the use of saxagliptin. In the high-risk population of the SAVOR-TIMI trial, overall $12.6 \%$ of the population had events as defined by the secondary efficacy end point with $3.5 \%$ of patients under saxagliptin being hospitalized for heart failure in comparison to $2.8 \%$ of those under placebo, HR (95\% CI) 1.27 (1.07-1.51) [32]. In our lower risk population, cardiovascular events were not frequent, heart failure was reported in only three patients $(0.3 \%)$, and it was not related with saxagliptin therapy; thus, heart failure does not seem to be an issue in this context.

Approximately $11 \%$ of participants had moderate or severe renal impairment at baseline, and 80 developed renal disorders (primarily microalbuminuria) during follow-up. Severe renal impairment is associated with an increased risk of hypoglycemia [39], while any degree of renal dysfunction is an independent cardiovascular risk factor in people with type 2 diabetes [40, 41]. The available evidence [40-42] indicates that DPP-4 inhibitors may be a favorable choice as a glucose-lowering therapy in patients with renal diabetic complications. This is reinforced by the low risk of hypoglycemia with saxagliptin, compared with insulin or sulfonylureas, as seen in the present study.

\section{Study Limitations}

Observational studies such as this are subject to potential biases resulting from the self-selection of participating physicians and the selection of eligible patients by the physicians. As discussed above, the data suggest that the participating physicians were representative of physicians practicing in France. The possibility of bias in patient selection cannot be excluded, but it should be noted that physicians were asked to enroll participants sequentially without exclusion criteria other than participation in a clinical trial. It should also be noted that $61 \%$ of the participants were prescribed saxagliptin at enrollment into the study. However, the characteristics of those who were prescribed saxagliptin before vs. at inclusion in this study were very similar: $60 \%$ vs. $58 \%$ male, with mean age 62 vs. 61 years, respectively, with identical mean diabetes duration (7 years), BMI $(29.8 \mathrm{~kg} /$ $\mathrm{m}^{2}$ ) and HbA1c at saxagliptin initiation (8.0\%). A further limitation is that data on fasting and post-prandial plasma glucose were not available, although improvements in these measures are known benefits of DPP-4 inhibitor therapy [7].

\section{CONCLUSIONS}

This study has shown that saxagliptin is efficacious in a real-world practice setting. In routine clinical practice, saxagliptin was associated with a decrease in HbA1c of approximately $1.0 \%$ and was well tolerated with a low rate of severe hypoglycemia. The retention rate for continuing treatment over the 2 years with saxagliptin was high, $84 \%$ in general practitioners and 58\% in endocrinologists/diabetologists.

\section{ACKNOWLEDGEMENTS}

The authors thank all physicians and patients who participated in the study. Financial support 
for this study was provided by AstraZeneca, France, who have also paid the charges for processing this article. In addition, the authors would like to thank Françoise Bugnard and Philippe Huot-Marchand from the Mapi Group for providing statistical support and analysis. Medical writing assistance in the preparation of this article was provided by Dr. Michael Shaw (Anagram Communications Ltd., UK), funded by AstraZeneca, France. All authors meet the International Committee of Medical Journal Editors (ICMJE) criteria for authorship for this manuscript. All authors had full access to all of the data in this study and take complete responsibility for the integrity of the work as a whole, and the accuracy of the data analysis, and have given final approval to the version to be published.

Disclosures. Beverley Balkau has received fees for advisory boards and conference attendance from AstraZeneca and Sanofi. Bernard Charbonnel has received fees for advisory boards or speaker bureaus from AstraZeneca, Boehringer-Ingelheim, Lilly, Merck-Sharpe and Dohme, Novo-Nordisk, Sanofi and Takeda. Alfred Penfornis has received fees for consultancy, advisory boards, speaking, travel or accommodation from Ascencia, LifeScan, Sanofi, Lilly, Novartis, MSD, AstraZeneca, Abbott, Novo Nordisk and Medtronic. Bruno Detournay is associate director of Cemka-Eval, a research organization contracting with numerous French or international companies and public institutions in the field of health care. Florence Thomas-Delecourt is a salaried employee of AstraZeneca, France. Nora Chraibi is a salaried employee of AstraZeneca, France. Amir Lahouegue is a salaried employee of AstraZeneca, France. Céline Faure is an employee of the Mapi Group, which was hired by AstraZeneca to conduct the DIAPAZON study.

Compliance with Ethics Guidelines. All procedures followed were in accordance with the ethical standards of the responsible committee on human experimentation (institutional and national) and with the Helsinki Declaration of 1964. Informed oral consent was obtained from all patients for being included in the study. In accordance with European regulations, ethical approval was not necessary for this observational study, because no additional therapy or monitoring was required.

Data Availability. The data sets generated and/or analyzed during the current study are available from the corresponding author on reasonable request.

Open Access. This article is distributed under the terms of the Creative Commons Attribution-NonCommercial 4.0 International License (http://creativecommons.org/licenses/ by-nc/4.0/), which permits any noncommercial use, distribution, and reproduction in any medium, provided you give appropriate credit to the original author(s) and the source, provide a link to the Creative Commons license, and indicate if changes were made.

\section{REFERENCES}

1. International Diabetes Federation. IDF Diabetes Atlas, 7th ed. 2015. http://www.diabetesatlas.org/ across-the-globe.html. Accessed 27 Aug 2017.

2. Données épidémiologiques. Prévalence et incidence $\mathrm{du}$ diabète. http://invs.santepubliquefrance.fr/ Dossiers-thematiques/Maladies-chroniques-et-trauma tismes/Diabete. Accessed 27 Aug 2017.

3. Fosse-Edorh S, Mandereau-Bruno L, Regnault N. The burden of diabetes-related complications in France in 2013. Summary and perspectives. Bull Epidémiol Hebd. 2015;34-35:619-25. http://invs. santepubliquefrance.fr/beh/2015/34-35/pdf/2015_ 34-35_1.pdf. Accessed 27 Aug 2017.

4. Nauck M. Incretin therapies: highlighting common features and differences in the modes of action of glucagon-like peptide-1 receptor agonists and dipeptidyl peptidase-4 inhibitors. Diabetes Obes Metab. 2016;18:203-16.

5. Kawanami D, Matoba K, Sango K, Utsunomiya K. Incretin-based therapies for diabetic complications: basic mechanisms and clinical evidence. Int J Mol Sci. 2016;17:E1223.

6. Omar B, Ahrén B. Pleiotropic mechanisms for the glucose-lowering action of DPP-4 inhibitors. Diabetes. 2014;63:2196-202. 
7. Sjöstrand M, Wei C, Cook W, et al. Assessment of saxagliptin efficacy: meta-analysis of 14 phase 2 and 3 clinical trials. Diabetes Ther. 2017;8:587-99.

8. Hinnen D. Dipeptidyl peptidase-4 inhibitors in diverse patient populations with type 2 diabetes. Diabetes Educ. 2015;41(1 Suppl):19S-31S.

9. Dhillon S. Saxagliptin: a review in type 2 diabetes. Drugs. 2015;75:1783-96.

10. Ceriello A, Sportiello L, Rafaniello C, Rossi F. DPP-4 inhibitors: pharmacological differences and their clinical implications. Expert Opin Drug Saf. 2014;13(Suppl 1):S57-68.

11. Chen XW, He ZX, Zhou ZW, et al. Clinical pharmacology of dipeptidyl peptidase 4 inhibitors indicated for the treatment of type 2 diabetes mellitus. Clin Exp Pharmacol Physiol. 2015;42:999-1024.

12. Wang A, Dorso C, Kopcho L, et al. Potency, selectivity and prolonged binding of saxagliptin to DPP4: maintenance of DPP4 inhibition by saxagliptin in vitro and ex vivo when compared to a rapidly-dissociating DPP4 inhibitor. BMC Pharmacol. $2012 ; 12: 2$.

13. Rosenstock J, Aguilar-Salinas C, Klein E, et al. Effect of saxagliptin monotherapy in treatment-naïve patients with type 2 diabetes. Curr Med Res Opin. 2009;25:2401-11.

14. Jadzinsky M, Pfützner A, Paz-Pacheco E, et al. Saxagliptin given in combination with metformin as initial therapy improves glycaemic control in patients with type 2 diabetes compared with either monotherapy: a randomized controlled trial. Diabetes Obes Metab. 2009;11:611-22.

15. DeFronzo RA, Hissa MN, Garber AJ, et al. The efficacy and safety of saxagliptin when added to metformin therapy in patients with inadequately controlled type 2 diabetes with metformin alone. Diabetes Care. 2009;32:1649-55.

16. Göke B, Gallwitz B, Eriksson J, Hellqvist A, Gause-Nilsson I, D1680C00001 Investigators. Saxagliptin is non-inferior to glipizide in patients with type 2 diabetes mellitus inadequately controlled on metformin alone: a 52-week randomised controlled trial. Int J Clin Pract. 2010;64:1619-31.

17. Scheen AJ, Charpentier G, Ostgren CJ, Hellqvist A, Gause-Nilsson I. Efficacy and safety of saxagliptin in combination with metformin compared with sitagliptin in combination with metformin in adult patients with type 2 diabetes mellitus. Diabetes Metab Res Rev. 2010;26:540-9.
18. Chacra AR, Tan GH, Apanovitch A, Ravichandran S, List J, Chen R, CV181-040 Investigators. Saxagliptin added to a submaximal dose of sulphonylurea improves glycaemic control compared with uptitration of sulphonylurea in patients with type 2 diabetes: a randomised controlled trial. Int J Clin Pract. 2009;63:1395-406.

19. Hollander P, Li J, Allen E, Chen R, CV181-013 Investigators. Saxagliptin added to a thiazolidinedione improves glycemic control in patients with type 2 diabetes and inadequate control on thiazolidinedione alone. J Clin Endocrinol Metab. 2009;94:4810-9.

20. Moses RG, Kalra S, Brook D, et al. A randomized controlled trial of the efficacy and safety of saxagliptin as add-on therapy in patients with type 2 diabetes and inadequate glycaemic control on metformin plus a sulphonylurea. Diabetes Obes Metab. 2014;16:443-50.

21. Barnett AH, Charbonnel B, Donovan M, Fleming D, Chen R. Effect of saxagliptin as add-on therapy in patients with poorly controlled type 2 diabetes on insulin alone or insulin combined with metformin. Curr Med Res Opin. 2012;28:513-23.

22. Onglyza Summary of Product Characteristics. http://ec.europa.eu/health/documents/communityregister/html/h545.htm. Accessed 27 Aug 2017.

23. Komboglyze Summary of Product Characteristics. http://ec.europa.eu/health/documents/communityregister/html/h731.htm. Accessed 27 Aug 2017.

24. AFSSAPS - HAS. Type 2 diabetes treatment: French recommendations for good practice AFSSAPSHAS.2006. Diabetes Metab. 2006;32:643-8.

25. Caisse nationale de l'Assurance Maladie des travailleurs salariés (CNAMTS). Améliorer la qualité du système de santé et maîtriser les dépenses. Propositions de l'Assurance Maladie pour 2016. Rapport au ministre chargé de la Sécurité sociale et au Parlement sur l'évolution des charges et des produits de l'Assurance Maladie au titre de 2016 (loi du 13 août 2004). 2015. http://www.ameli.fr/l-assurancemaladie/statistiques-et-publications/rapports-et-peri odiques/rapports-charges-produits-de-l-assurancemaladie/rapports-charges-et-produits-pour-2013-a2017/rapport-charges-et-produits-pour-l-annee-2016. php. Accessed 27 Aug 2017.

26. Sicart D. Les médecins au 1er janvier 2013, Document de travail, Série statistiques, no 179, Drees, avril. 2013. http://drees.social-sante.gouv.fr/etudeset-statistiques/publications/documents-de-travail/ serie-statistiques/article/les-medecins-au-1er-janvier2013. Accessed 27 Aug 2017. 
27. Garber AJ, Abrahamson MJ, Barzilay JI, et al. AACE/ ACE comprehensive diabetes management algorithm 2015. Endocr Pract. 2015;21:438-47.

28. American Diabetes Association. Approaches to diabetes treatment. Diabetes Care. 2015;38(Suppl $1): S 41-8$.

29. Toth PP. Overview of saxagliptin efficacy and safety in patients with type 2 diabetes and cardiovascular disease or risk factors for cardiovascular disease. Vasc Health Risk Manag. 2014;11:9-23.

30. HAS ANSM Recommandation de bonne pratique. Stratégie médicamenteuse du contrôle glycémique du diabète de type 2. 2013. http://www.has-sante. $\mathrm{fr} /$ portail/upload/docs/application/pdf/2013-02/10 irp04_reco_diabete_type_2.pdf. Accessed 26 Aug 2017.

31. Jain R. Utility of saxagliptin in the treatment of type 2 diabetes: review of efficacy and safety. Adv Ther. 2015;32:1065-84.

32. Scirica BM, Bhatt DL, Braunwald E, et al. Saxagliptin and cardiovascular outcomes in patients with type 2 diabetes mellitus. N Engl J Med. 2013;369:1317-26.

33. Druet C, Bourdel-Marchasson I, Weill A, et al. Type 2 diabetes in France: epidemiology, trends of medical care, social and economic burden. Presse Med. 2013;42:830-8.

34. Eschwege E, Basdevant A, Crine A, et al. Type 2 diabetes mellitus in France in 2012: results from the ObEpi survey. Diabetes Metab. 2015;41:55-61.

35. Simon D, Detournay B, Eschwege E, et al. Use of vildagliptin in management of type 2 diabetes: effectiveness, treatment persistence and safety from the 2-year real-life VILDA study. Diabetes Ther. 2014;5:207-24.

36. Valensi P, de Pouvourville G, Benard $\mathrm{N}$, et al. Treatment maintenance duration of dual therapy with metformin and sitagliptin in type 2 diabetes: the ODYSSEE observational study. Diabetes Metab. $2015 ; 41: 231-8$.

37. Amori RE, Lau J, Pittas AG. Efficacy and safety of incretin therapy in type 2 diabetes: systematic review and meta-analysis. JAMA. 2007;298:194-206.

38. Davidson JA. Tolerability of saxagliptin in patients with inadequately controlled type 2 diabetes: results from 6 phase III studies. J Manag Care Pharm. 2014;20:120-9.

39. Gianchandani RY, Neupane S, Iyengar JJ, Heung M. Pathophysiology and management of hypoglycemia in end-stage renal disease patients: a review. Endocr Pract. 2017;23:353-62.

40. Howse PM, Chibrikova LN, Twells LK, Barrett BJ, Gamble JM. Safety and efficacy of incretin-based therapies in patients with type 2 diabetes mellitus and CKD: a systematic review and meta-analysis. Am J Kidney Dis. 2016;68:733-42.

41. Thomas MC, Paldánius PM, Ayyagari R, Ong SH, Groop PH. Systematic literature review of DPP-4 inhibitors in patients with type 2 diabetes mellitus and renal impairment. Diabetes Ther. 2016;7:439-54.

42. Davies M, Chatterjee S, Khunti K. The treatment of type 2 diabetes in the presence of renal impairment: what we should know about newer therapies. Clin Pharmacol. 2016;8:61-81. 